\title{
Thermal Storage of (Solar) Energy by Sorption of Water in Magnesium (Hydro) Carbonates
}

\author{
Rickard Erlund*, Ron Zevenhoven \\ Åbo Akademi University, Thermal and Flow Engineering Laboratory \\ Piispankatu 8, 20500 Turku Finland \\ e-mail: rerlund@abo.fi
}

Received 09 December 2016, Revised 03 February 2017, Accepted 07 February 2017

\begin{abstract}
In this paper the thermodynamic properties and the chemical reaction kinetics of the reversible reactions where sorption of water in magnesium hydro carbonates are analysed for thermal energy storage (TES). Depending on the conditions mainly nesquehonite, lansfordite and hydromagnesite may be formed from magnesite, all with a certain heat effect. Magnesite and water vapour can form nesquehonite or lansfordite via reaction (R1) and (R2):

$\mathrm{MgCO}_{3}+3 \mathrm{H}_{2} \mathrm{O}(\mathrm{g}) \leftrightarrow \mathrm{MgCO}_{3} \cdot 3 \mathrm{H}_{2} \mathrm{O}$

$\Delta \mathrm{H}=-1.0 \mathrm{MJ} / \mathrm{kg} \mathrm{MgCO} \cdot 3 \mathrm{H}_{2} \mathrm{O}, \mathrm{T}=298 \mathrm{~K}$

$\mathrm{MgCO}_{3}+5 \mathrm{H}_{2} \mathrm{O}(\mathrm{g}) \leftrightarrow \mathrm{MgCO}_{3} \cdot 5 \mathrm{H}_{2} \mathrm{O}$

$\Delta \mathrm{H}=-1.41 \mathrm{MJ} / \mathrm{kg} \mathrm{MgCO} 3 \cdot 5 \mathrm{H}_{2} \mathrm{O}, \mathrm{T}=298 \mathrm{~K}$

Compared to other chemical sorption compounds, its advantages are low operating temperatures while they can act as a fire retardant. Experimental data is presented on the reactivity of the dehydration at various temperatures. The rate of dehydration of the nesquehonite is sufficient at low temperatures such as $50{ }^{\circ} \mathrm{C}$ and the reaction is about 90 $\%$ completed after 120 minutes. Magnesite reaches partial re-hydration to about $37 \%$ conversion after 24 hours. For better contact between reagents, mixtures with silica gel were used. A too large amount of water vapour, causing condensation of the water, appears to make the reactions irreversible. The temperatures of operating the process are presented as well as which compounds give an optimal energy storage.
\end{abstract}

Keywords: Thermal energy storage; magnesium carbonate; reversible reaction; nesquehonite.

\section{Introduction}

The challenge of meeting heat use with heat production could be solved with thermal energy storage (TES). Especially attractive are renewable sources such as thermal solar energy. The higher use of heat during night-time, caused by a lower temperature, and with sunlight energy available during daytime, requires storage of the heat.

The most energy dense solutions for storage are reversible chemical reactions with high reaction enthalpies reacting spontaneously at suitable temperatures. This usually requires temperatures $200-1000{ }^{\circ} \mathrm{C}$ depending on the compound, which is above temperatures used in most existing heating systems [1]. For lower and more widely applicable temperatures $\left(100-150{ }^{\circ} \mathrm{C}\right)$ chemical sorption of water in a salt or silica based compounds can be used. According to van Essen et al. Epsom salt $\left(\mathrm{MgSO}_{4} \cdot 7 \mathrm{H}_{2} \mathrm{O}\right)$ is the most interesting compound for this, considering its high theoretical energy capacity of $1.74 \mathrm{MJ} / \mathrm{kg}$ thermal storage [2]. However, studies showed that using Epsom salt combined with Zeolite $13 \mathrm{X}$ to improve the heat storage capacity of the zeolite, has the opposite effect on the zeolite [3]. Whiting et al. showed that $\mathrm{MgSO}_{4}$ was not able to utilize its full sorption capacity and the use of zeolite with $\mathrm{MgSO}_{4}$ gave no considerable effect on the storage capacity.

Using 15 wt- $\% \mathrm{MgSO}_{4}$ combined with zeolite $\mathrm{Na}-\mathrm{Y}$ showed a heat capacity of $1,1 \mathrm{MJ} / \mathrm{kg}$ compared to 1,0 $\mathrm{MJ} / \mathrm{kg}$ with only the zeolite. Another zeolite, $\mathrm{H}-\mathrm{Y}$, with a heat capacity of $0.8 \mathrm{MJ} / \mathrm{kg}$ can be about $90 \%$ dehydrated at $100{ }^{\circ} \mathrm{C}$, which is about $40{ }^{\circ} \mathrm{C}$ lower than given in [4].
Another molecular sieve, silica gel, with a pore size of 2-3 $\mathrm{nm}$ showed that about 2.3-2.4 MJ/kg can be stored per $\mathrm{kg}$ water absorbed, but can be operated only at lower temperatures [5]. Dehydration at $60{ }^{\circ} \mathrm{C}$ would give a capacity of $0.52 \mathrm{MJ} / \mathrm{kg}$ and $100{ }^{\circ} \mathrm{C}$ a capacity of 0.62 $\mathrm{MJ} / \mathrm{kg}$. Moreover, operating temperatures have been lowered by others to a suitable temperature for the sorption reactions of $\mathrm{CaCl}_{2}$ and $\mathrm{MgCl}_{2}$ by operating at $150 \mathrm{mbar}$ and 88 mbar, respectively [6].

In this article sorption of water by magnesite producing lansfordite and nesquehonite is examined for TES. These minerals can theoretically store less heat than Epsom salt and $\mathrm{CaCl}_{2}$, but have the advantage of lower operating temperatures, which leads to efficient solar energy and applicable in combination with district heating [7].

Nesquehonite $\left(\mathrm{MgCO}_{3} \cdot 3 \mathrm{H}_{2} \mathrm{O}\right)$ and magnesite $\left(\mathrm{MgCO}_{3}\right)$ are products of a carbon capture storage by mineralisation (CCSM) process, possibly making it an inexpensive resource. Basically magnesium is extracted from serpentine mineral, a magnesium silicate. The extracted magnesium is carbonated with $\mathrm{CO}_{2}$ in water solution forming nesquehonite or in a pressured fluidised bed giving magnesite [8-10]. By adding potassium dihydrogen phosphate $\left(\mathrm{KH}_{2} \mathrm{PO}_{4}\right)$ lansfordite $\left(\mathrm{MgCO}_{3} \cdot 5 \mathrm{H}_{2} \mathrm{O}\right)$ can be precipitated from $\mathrm{Mg}(\mathrm{OH})_{2}$ in water [11]. Conditions with low $\mathrm{CO}_{2}$ vapour pressure in the surrounding gas can result in reduction of $20 \% \mathrm{CO}_{2}$ of the nesquehonite, in the $\mathrm{Mg}$ $\mathrm{CO}_{3}-\mathrm{H}_{2} \mathrm{O}$ system, forming hydromagnesite irreversibly, shown in reaction (R3) below [12]. 
At a temperature of $95^{\circ} \mathrm{C}$ nesquehonite decomposes in a closed system, where the released water vapour gets trapped, containing $50 \%$ air with additional $20 \%$ of $\mathrm{N}_{2}$ and $30 \%$ of $\mathrm{CO}_{2}$ in 3 hours. However, in a continuously flushed system, where the released water vapours are removed giving lower relative humidity $(\mathrm{RH})$, it decomposes in 20 minutes. While, at $50{ }^{\circ} \mathrm{C}$ nesquehonite fully decomposes in dry conditions in 2-3 hours [13]. Theoretically, $\mathrm{MgCO}_{3}$ hydrated to nesquehonite or lansfordite gives an energy storage capacity per ton up to 6 respectively 8 times better than heating up water by $40{ }^{\circ} \mathrm{C}[14]$.

$\mathrm{MgCO}_{3}+3 \mathrm{H}_{2} \mathrm{O}(\mathrm{g}) \leftrightarrow \mathrm{MgCO}_{3} \cdot 3 \mathrm{H}_{2} \mathrm{O}$

$\Delta \mathrm{H}=-1.0 \mathrm{MJ} / \mathrm{kg} \mathrm{MgCO}_{3} \cdot 3 \mathrm{H}_{2} \mathrm{O}, \mathrm{T}=298 \mathrm{~K}$

$\mathrm{MgCO}_{3}+5 \mathrm{H}_{2} \mathrm{O}(\mathrm{g}) \leftrightarrow \mathrm{MgCO}_{3} \cdot 5 \mathrm{H}_{2} \mathrm{O}$

$\Delta \mathrm{H}=-1,41 \mathrm{MJ} / \mathrm{kg} \mathrm{MgCO}_{3} \cdot 5 \mathrm{H}_{2} \mathrm{O}, \mathrm{T}=298 \mathrm{~K}$

In a mildly alkaline solution the following reaction produces hydromagnesite with a much smaller heat effect:

$5 \mathrm{MgCO}_{3}+2 \mathrm{OH}^{-}(\mathrm{aq})+4 \mathrm{H}_{2} \mathrm{O}(\mathrm{g}) \leftrightarrow$
$\mathrm{Mg}_{5}(\mathrm{OH})_{2}\left(\mathrm{CO}_{3}\right)_{4} \cdot 4 \mathrm{H}_{2} \mathrm{O}+\mathrm{CO}_{3}{ }^{2-}(\mathrm{aq})$
$\Delta \mathrm{H}=-192 \mathrm{~kJ} / \mathrm{kg} \mathrm{MgCO}_{3}, \mathrm{~T}=298 \mathrm{~K}$

$5 \mathrm{MgCO}_{3}+2 \mathrm{OH}^{-}(\mathrm{aq})+4 \mathrm{H}_{2} \mathrm{O}(\mathrm{l}) \leftrightarrow$

$\mathrm{Mg}_{5}(\mathrm{OH})_{2}\left(\mathrm{CO}_{3}\right)_{4} \cdot 4 \mathrm{H}_{2} \mathrm{O}+\mathrm{CO}_{3}{ }^{2-}(\mathrm{aq})$

$\Delta \mathrm{H}=-30 \mathrm{~kJ} / \mathrm{kg} \mathrm{MgCO}_{3}, \mathrm{~T}=298 \mathrm{~K}$

In practice, this could take place in a storage tank located below a house, or possibly in the wall of a house. Technology can be developed for heating a house or other building that uses daytime solar energy to drive the endothermic reactions while during night-time the reverse reaction will generate heat for the building. Studies show that dehydrated magnesium hydro carbonates will remain in their original form after two weeks in a relative humidity $70 \%$ for two weeks [15]. This being suitable for seasonal storage, also a small part of the storage tank could be used for night-time heating using daytime solar energy during spring and autumn. This setup is more usable for locations where winter-time solar power is limited, or heat usage is considerably higher. In case of fire, using a $\mathrm{MgCO}_{3} \cdot 3 \mathrm{H}_{2} \mathrm{O}$ compound for energy storage in house is favourable since it acts as a flame retardant. Firstly, the $\mathrm{H}_{2} \mathrm{O}$ will be released at temperatures as $100-117{ }^{\circ} \mathrm{C}$, and at $423{ }^{\circ} \mathrm{C} \mathrm{CO}_{2}$ will be released [16, 17]. Higher partial pressure of $\mathrm{CO}_{2}$ and $\mathrm{H}_{2} \mathrm{O}$ will act as inert gas in case of fire [17].

\section{Experiments}

\subsection{Synthesis of Nesquehonite (NQ)}

In a CCSM process nesquehonite (NQ) can be prepared via precipitation of a $\mathrm{MgSO}_{4}$ solution by adding $\mathrm{NH}_{4} \mathrm{OH}$ and absorbed $\mathrm{CO}_{2}[8,9]$. Neither $\mathrm{MgCO}_{3}$ nor $\mathrm{MgCO}_{3} \cdot 3 \mathrm{H}_{2} \mathrm{O}$ is soluble in water. Depending on temperature and vapour pressures either reaction (R4), forming hydromagnesite and ammonium sulphate, or reaction (R5), forming NQ and ammonium sulphate will take place. At temperatures above $50{ }^{\circ} \mathrm{C}$ (R4) is preferred over (R5), but also at lower temperature with partial pressure of $\mathrm{CO}_{2}$ under 0.01 bar (R4) is favoured over (R5) [8].

$5 \mathrm{MgSO}_{4}(\mathrm{~s})+10 \mathrm{H}_{2} \mathrm{O}(\mathrm{l})+10 \mathrm{NH}_{3}(\mathrm{~g})+4 \mathrm{CO}_{2}(\mathrm{~g})$
$\leftrightarrow \mathrm{Mg}_{5}(\mathrm{OH})_{2}\left(\mathrm{CO}_{3}\right)_{4} \cdot 4 \mathrm{H}_{2} \mathrm{O}(\mathrm{s})+5\left(\mathrm{NH}_{4}\right)_{2} \mathrm{SO}_{4}(\mathrm{aq})$

$\mathrm{MgSO}_{4}(\mathrm{~s})+2 \mathrm{NH}_{3}(\mathrm{~g})+\mathrm{CO}_{2}(\mathrm{~g})+4 \mathrm{H}_{2} \mathrm{O}(\mathrm{l})$ $\leftrightarrow \quad \mathrm{MgCO}_{3} \cdot 3 \mathrm{H}_{2} \mathrm{O}(\mathrm{s})+\left(\mathrm{NH}_{4}\right)_{2} \mathrm{SO}_{4}(\mathrm{aq})$

A solution was prepared with 0.81 of $1 \mathrm{~mol} / \mathrm{l}$ anhydrous $\mathrm{MgSO}_{4}$ in a reactor. $\mathrm{CO}_{2}$ was fed to the solution as bubbles for 15 minutes lowering the $\mathrm{pH}$ to about 4.5 before adding the ammonia. At a $\mathrm{pH}$ values above approximately $9.3 \mathrm{NQ}$ precipitates. The final $\mathrm{pH}$ value for the precipitation was 9.6 containing 1.072 moles of dissolved $\mathrm{NH}_{3}$. The precipitate was filtered and dried for three days in a desiccator. During the precipitation, filtration and drying the partial pressure for $\mathrm{CO}_{2}$ was above 0.01 bar. According to Hill et al. at a partial pressure above 0.01 bar of $\mathrm{CO}_{2}$ at $25{ }^{\circ} \mathrm{C}$ hydromagnesite will not be formed [12]. A lower $\mathrm{CO}_{2}$ pressure may be a problem for the reversibility of the reactions, because $\mathrm{CO}_{2}$ is emitted when hydromagnesite is formed, as shown in reaction (R3), and the temperature required for this reaction is higher [14]. Moreover, hydromagnesite is considered a stable product disabling the process reversibility [8].

\subsection{Dehydration Test of Nesquehonite}

Shown in Table 1, 90\% of the reaction (R1) of NQ dehydration implies conversion into magnesite and water at $61{ }^{\circ} \mathrm{C}$, and $50 \%$ respectively at $45{ }^{\circ} \mathrm{C}$. Dehydration of NQ has been shown by Morgan et al. to occur at $50{ }^{\circ} \mathrm{C}$ [13]. Experiments were done in this work at $50,55,60$ and $65^{\circ} \mathrm{C}$ to determine the conversion and the reaction rate at the specified temperature, indicating the minimum operating temperature for a magnesium hydro carbonate based TES.

This was tested by heating up the NQ containing reactors surface, an Erlenmeyer flask in heated water bath, to the required temperature $\left(50-65{ }^{\circ} \mathrm{C}\right)$. A gas flow containing $\mathrm{CO}_{2}$ and moist air was prepared in a vessel and pumped though the reactor to remove the water excess vapour. The partial pressure for $\mathrm{CO}_{2}$ was 0.21 bar while for the water it was 0.012 bar $\left(\mathrm{RH} 80 \%\right.$ at $\left.20^{\circ} \mathrm{C}\right)$, pumped at a rate of $1 \mathrm{dm} 3 / \mathrm{min}$.

\subsection{Hydration of $\mathrm{MgCO}_{3}$}

Hydration tests with $\mathrm{MgCO}_{3}$ powder and dehydrated NQ were made to determine the behaviour and hydration of $\mathrm{MgCO}_{3}$ by incorporating crystal water, using the experimental set-up as shown in Figure 1. Hydration being the heat discharge step of a TES process, confirmation of the reaction and its sufficient rate is needed.

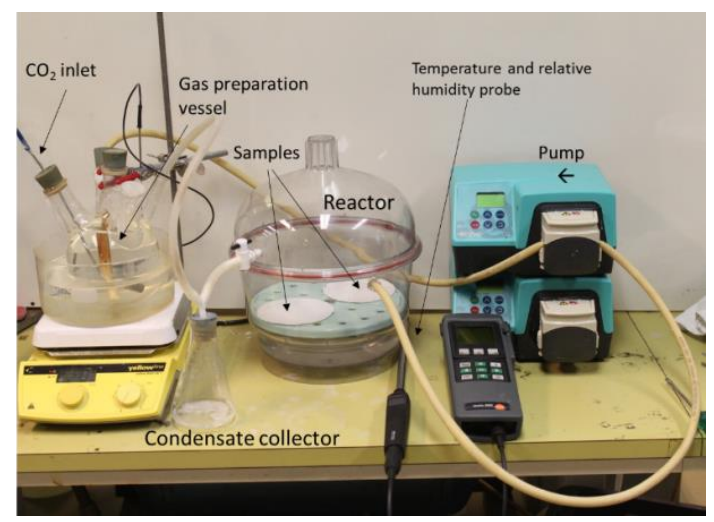

Figure 1. Setup for the hydration reactor and the gas humidity control vessel.

The water adsorption on $\mathrm{MgCO}_{3}$ was tested in a reactor with $20{ }^{\circ} \mathrm{C}$ air with $\mathrm{RH}$ of $70-75 \%$ containing 0.027 vol-\% $\mathrm{CO}_{2}$. 
The gas mixture was prepared in a separate vessel bubbling air and $\mathrm{CO}_{2}$ through $60{ }^{\circ} \mathrm{C}$ water. The gas from the preparation (gas humidity control) vessel was forced into the reactor, while the gas from the reactor is pumped $(0.2$ $1 / \mathrm{min}$ ) to the gas preparation vessel, giving a closed loop. This was continued until the gas inside the reactor reaches $75 \% \mathrm{RH}$. The reason for pumping $\mathrm{CO}_{2}$ through the water is to buffer the $\mathrm{CO}_{2}$ content and measure the $\mathrm{pH}$ to indicate the vapour pressure of $\mathrm{CO}_{2}$ in the system.

\section{Thermodynamics of the Reactions and Gibbs Energy Minimization}

The interesting points are the temperatures where $\Delta \mathrm{G}=$ 0 , being the points where the reactions are divided into dehydrating or hydrating ones. Table 1 shows that the dehydration of $\mathrm{MgCO}_{3} \cdot 3 \mathrm{H}_{2} \mathrm{O}$ above $45{ }^{\circ} \mathrm{C}$ and of $\mathrm{MgCO}_{3} \cdot 5 \mathrm{H}_{2} \mathrm{O}$ above $57{ }^{\circ} \mathrm{C}$ is spontaneous. However, the temperature should differ at least $10-20{ }^{\circ} \mathrm{C}$ from $\Delta \mathrm{G}=0$ to reach sufficiently fast and near total conversion for TES use. In Table 1, the point for $90 \%$ conversion of the dehydration reactions is shown as well to indicate what is the lowestoperating temperature if $90 \%$ conversion is desirable. For dehydrating NQ and lansfordite that is $61{ }^{\circ} \mathrm{C}$ and $65{ }^{\circ} \mathrm{C}$, respectively. These temperatures are suitable also when using solar panels during lower operating temperature periods when the solar intensity is lower. The kinetics and conversion grade at various temperatures were tested under laboratory conditions and discussed in section 4. The temperatures for the dehydration reaction of NQ forming hydromagnesite gives $\Delta \mathrm{G}=0$ at $72{ }^{\circ} \mathrm{C}$ considerably higher temperature.

Table 1 shows that the spontaneous dehydration of $\mathrm{MgSO}_{4} \cdot 7 \mathrm{H}_{2} \mathrm{O}$ requires temperatures over $145^{\circ} \mathrm{C}$. However, studies show that a temperature of $122{ }^{\circ} \mathrm{C}$ partly dehydrates the $\mathrm{MgSO}_{4} \cdot 7 \mathrm{H}_{2} \mathrm{O}$, still requiring external heat noting that heating systems for houses seldom use such a high temperature [3]. Using $\mathrm{CaCl}_{2}$, the operating temperatures can be lowered to $95^{\circ} \mathrm{C}$ by using a reduced pressure of 150 mbar [6].

A Gibbs energy minimization simulation was done using HSC8 software [14] for 1 mole $\mathrm{MgCO}_{3} \cdot 3 \mathrm{H}_{2} \mathrm{O}$ as a reactant. In Figure 2 the results are shown for equilibrium states from $0{ }^{\circ} \mathrm{C}$ to $100{ }^{\circ} \mathrm{C}$. The $\mathrm{H}_{2} \mathrm{O}$ (l) phase was left out as a possible product in the simulations because the reactions become irreversible with liquid water instead of vapour water. The results in Figure 2 (top), showed that below $55{ }^{\circ} \mathrm{C}$ mainly lansfordite would be formed besides $\mathrm{NQ}$, until all $\mathrm{H}_{2} \mathrm{O}(\mathrm{g})$ has reacted. At $57^{\circ} \mathrm{C}$ and at $71{ }^{\circ} \mathrm{C}$,

Table 1. Operation temperatures and specific heat storage capacity of various magnesium hydro carbonate and other potential sorption reactions.

\begin{tabular}{|c|c|c|c|c|c|c|}
\hline Reaction & $\begin{array}{l}\text { Hydration } \\
\text { temp. }\left({ }^{\circ} \mathrm{C}\right)\end{array}$ & $\begin{array}{c}\mathrm{T}(\Delta \mathrm{G}=0) \\
\left({ }^{\circ} \mathrm{C}\right)\end{array}$ & $\begin{array}{c}90 \% \\
\text { dehydr. } \\
\left({ }^{\circ} \mathrm{C}\right)\end{array}$ & $\begin{array}{l}\text { Dehydr. } \\
\text { temp. } \\
\left({ }^{\circ} \mathrm{C}\right)\end{array}$ & $\begin{array}{l}\text { Specific } \\
\text { capacity } \\
(\mathrm{MJ} / \mathrm{kg})\end{array}$ & $\begin{array}{l}\text { Specific } \\
\text { capacity } \\
\left(\mathrm{GJ} / \mathrm{m}^{3}\right)\end{array}$ \\
\hline $\mathrm{MgCO}_{3}+3 \mathrm{H}_{2} \mathrm{O}(\mathrm{g})=\mathrm{MgCO}_{3} \cdot 3 \mathrm{H}_{2} \mathrm{O}$ & $\sim 20$ & 45 & 61 & $60-65$ & 1,0 & 1,83 \\
\hline $\mathrm{MgCO}_{3}+3 \mathrm{H}_{2} \mathrm{O}(1)=\mathrm{MgCO}_{3} \cdot 3 \mathrm{H}_{2} \mathrm{O}$ & & Irrev. & Irrev. & & & \\
\hline $\mathrm{MgCO}_{3}+5 \mathrm{H}_{2} \mathrm{O}(\mathrm{g})=\mathrm{MgCO}_{3} \cdot 5 \mathrm{H}_{2} \mathrm{O}$ & $5-10$ & 55 & 66 & $65-70$ & 1,41 & 2,54 \\
\hline $\mathrm{MgCO}_{3}+5 \mathrm{H}_{2} \mathrm{O}(\mathrm{l})=\mathrm{MgCO}_{3} \cdot 5 \mathrm{H}_{2} \mathrm{O}$ & & Irrev. & Irrev. & & & \\
\hline $\mathrm{MgSO}_{4}+7 \mathrm{H}_{2} \mathrm{O}(\mathrm{g})=\mathrm{MgSO}_{4} \cdot 7 \mathrm{H}_{2} \mathrm{O}$ & $\sim 20$ & 145 & 153 & $122^{1)}$ & 1,70 & 2,9 \\
\hline $\mathrm{MgSO}_{4}+7 \mathrm{H}_{2} \mathrm{O}(\mathrm{l})=\mathrm{MgSO}_{4} \cdot 7 \mathrm{H}_{2} \mathrm{O}$ & & Irrev. & Irrev. & & & \\
\hline $\begin{array}{c}5 \mathrm{MgCO}_{3} \cdot 3 \mathrm{H}_{2} \mathrm{O} \\
=\mathrm{Mg}_{5}(\mathrm{OH})_{2}\left(\mathrm{CO}_{3}\right)_{4} \cdot 4 \mathrm{H}_{2} \mathrm{O}+\mathrm{CO}_{2}(\mathrm{~g})+10 \mathrm{H}_{2} \mathrm{O}(\mathrm{g})\end{array}$ & $\sim 20$ & 72 & 75 & $70-80$ & 0,82 & 1,46 \\
\hline $\begin{array}{c}5 \mathrm{MgCO}_{3} \cdot 3 \mathrm{H}_{2} \mathrm{O}+2 \mathrm{OH}^{-}(\mathrm{aq}) \\
=\mathrm{Mg}_{5}(\mathrm{OH})_{2}(\mathrm{CO} 3) 4 \cdot 4 \mathrm{H}_{2} \mathrm{O}+\mathrm{CO}_{3}(\mathrm{aq})+11 \mathrm{H}_{2} \mathrm{O}(\mathrm{l})\end{array}$ & & Irrev. & Irrev. & & & \\
\hline $\mathrm{MgCO}_{3} \cdot 3 \mathrm{H}_{2} \mathrm{O}+2 \mathrm{H}_{2} \mathrm{O}(\mathrm{g})=\mathrm{MgCO}_{3} * 5 \mathrm{H}_{2} \mathrm{O}$ & $\sim 20$ & 74 & 97 & $95-100$ & 0,63 & 1,06 \\
\hline $\mathrm{MgCO}_{3} \cdot 3 \mathrm{H}_{2} \mathrm{O}+2 \mathrm{H}_{2} \mathrm{O}(1)=\mathrm{MgCO}_{3} * 5 \mathrm{H}_{2} \mathrm{O}$ & $\sim 0$ & $\sim 8$ & 86 & & 0,15 & 0,25 \\
\hline $2 \mathrm{H}_{2} \mathrm{O}\left(20^{\circ} \mathrm{C}\right)=2 \mathrm{H}_{2} \mathrm{O}\left(60^{\circ} \mathrm{C}\right)$ & $20^{2)}$ & - & - & $60^{2)}$ & 0,17 & 0,17 \\
\hline Silica Gel & $\sim 20$ & - & - & 100 & 0,62 & \\
\hline Silica Gel dehydrated at $65^{\circ} \mathrm{C}$ & $\sim 20$ & - & - & 65 & 0,52 & \\
\hline Zeolite HY (dehydr.) = Zeolite HY (hydr.) 「4† & $\sim 20$ & - & $\sim 110$ & 110 & 0,8 & \\
\hline Zeolite Na-Y (dehydr.) = Zeolite Na-Y (hydr.) [4] & $\sim 20$ & - & $\sim 140$ & 140 & 1,0 & \\
\hline $\mathrm{CaSO}_{4}+2 \mathrm{H}_{2} \mathrm{O}(\mathrm{g})=\mathrm{CaSO}_{4} \cdot 2 \mathrm{H}_{2} \mathrm{O}$ & 20 & 89 & 115 & $110-120$ & & 1,3 \\
\hline
\end{tabular}

1) Partly dehydrates at $122{ }^{\circ} \mathrm{C}$ [3]. 2) The required operating temperatures for using water as latent heat storage with a $\triangle T$ of $40^{\circ} \mathrm{C}$. 
0.5 moles and 0.9 of magnesite will be formed, respectively. However, studies showed that lansfordite is converted to NQ at room temperature and, as shown in Table 1, the reaction between lansfordite and NQ shows that $\Delta \mathrm{G}=0$ at $8{ }^{\circ} \mathrm{C}[14,18]$. Magnesite is found at the lower temperatures, as the water vapour to form lansfordite is not sufficient, considering that the reactant NQ contains two crystal water molecules less. The same Gibbs energy minimization case without lansfordite as a possible product is shown in Figure 2 (bottom), resulting in 0.5 moles and 0.9 of magnesite formed at $45^{\circ} \mathrm{C}$ and at $61{ }^{\circ} \mathrm{C}$, respectively. This corresponds to reaction (R1).

Equilibrium Amount, kmol

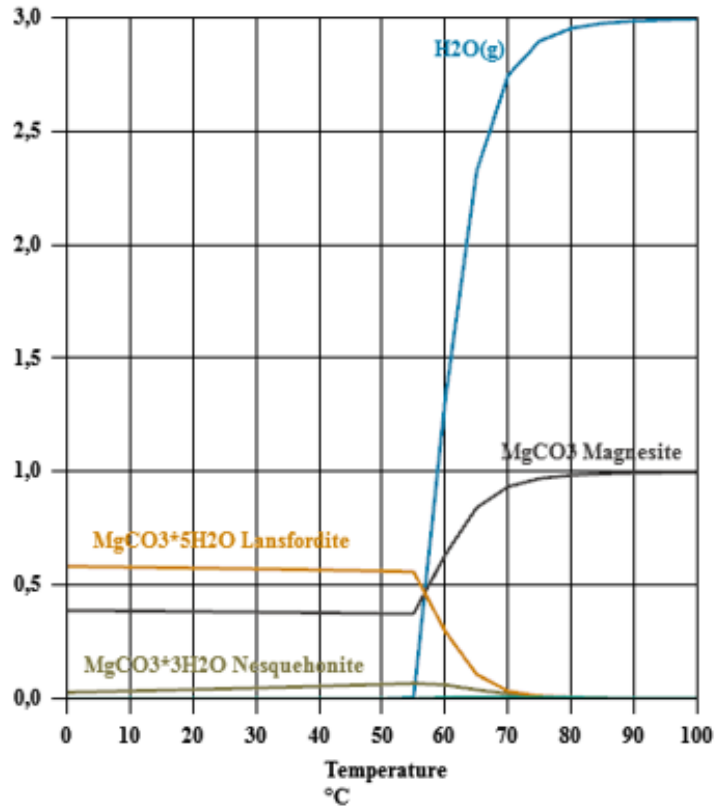

Equilibrium Amount, kmol

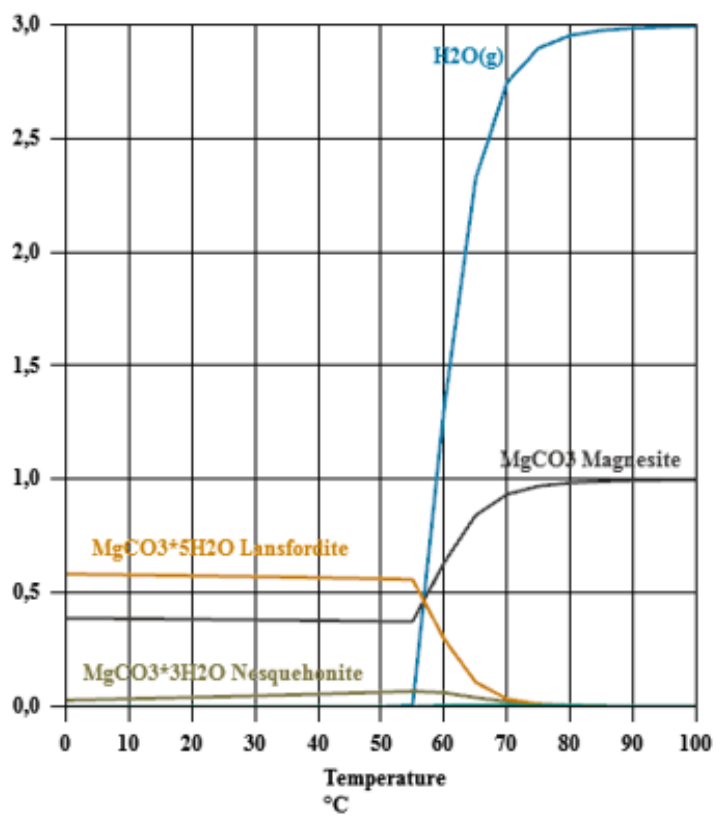

Figure 2. Gibbs energy minimization with $\mathrm{MgCO}_{3} \cdot 3 \mathrm{H}_{2} \mathrm{O}$ as reactant. In the top figure lansfordite is allowed as product, in the bottom figure lansfordite is not.

The large amounts of water vapour released during decomposition may condense, making the reaction irreversible. To obtain the reaction reversibility, the water vapour can be adsorbed with zeolite or silica gel or collected in a separate tank.

\section{Results and Discussion}

\subsection{Dehydration of Nesquehonite (NQ)}

Dehydration characteristics of NQ produced via the synthesis described in section 2.1, are tested to confirm the reversibility of the reaction and investigating the reaction rates for the thermal energy charging step of the heat storage process. As mentioned earlier, a 90\% dehydration or leftward conversion of reaction (R1) is theoretically taking place at $61{ }^{\circ} \mathrm{C}$. Figure 3 shows that the dehydration experiment of NQ after 2 hours at $60{ }^{\circ} \mathrm{C}$ reaches a conversion of $93 \%$ and at $65{ }^{\circ} \mathrm{C}$ almost $100 \%$. These results basically match the theoretical figures, considering possible measuring errors and the fact that the NQ may contain residuals of the reactants it was produced from.

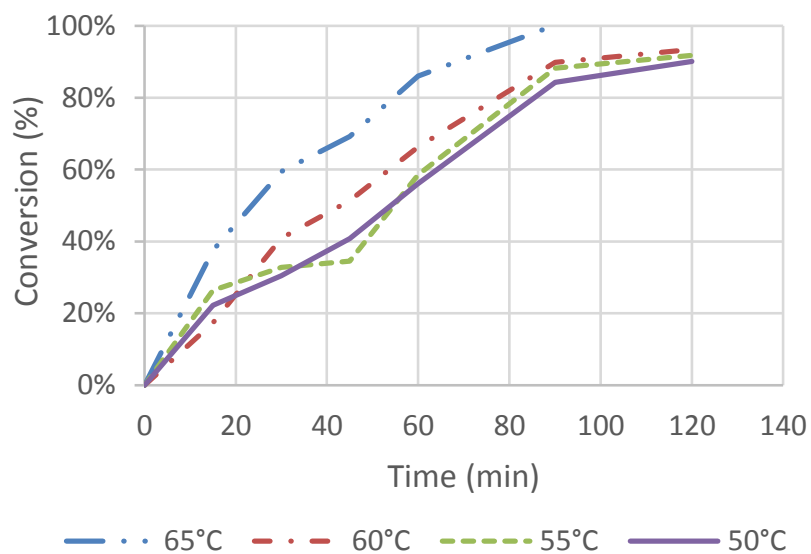

Figure 3. NQ dehydration at various temperatures after 0 120 minutes.

Shown in Figure 4, the theoretical conversion calculated by Gibbs free energy minimisation compared with conversion results after 120 minutes. After fluctuating for the first 60 minutes of the experiments of 50 and $55^{\circ} \mathrm{C}$, the next 60 minutes follow the trend of experiment with $60{ }^{\circ} \mathrm{C}$, with a conversion of $90 \%$ and $92 \%$, respectively. However, shown in Figure 4, theoretically the conversion is $72 \%$ and $90 \%$, respectively. Similar results were obtained in a continuously flushed system at $50{ }^{\circ} \mathrm{C}$ in the studies of Morgan et al., while in a closed and wet system almost no conversion was found [13]. The results given here show that an operating temperature of $50{ }^{\circ} \mathrm{C}$ is sufficient for de dehydration, the heat charging step of the process.

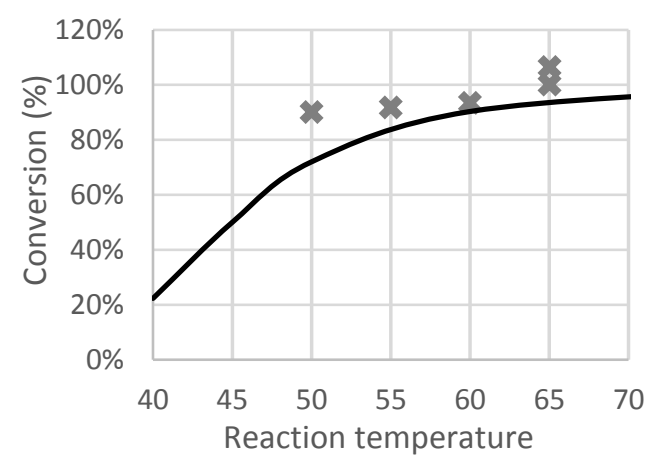

* Experimenta

- Gibbs free energy minimisation software

Figure 4. Theoretical conversion calculated by Gibbs free energy minimisation software compared with conversion results after 120 minutes. (HSC 8). 


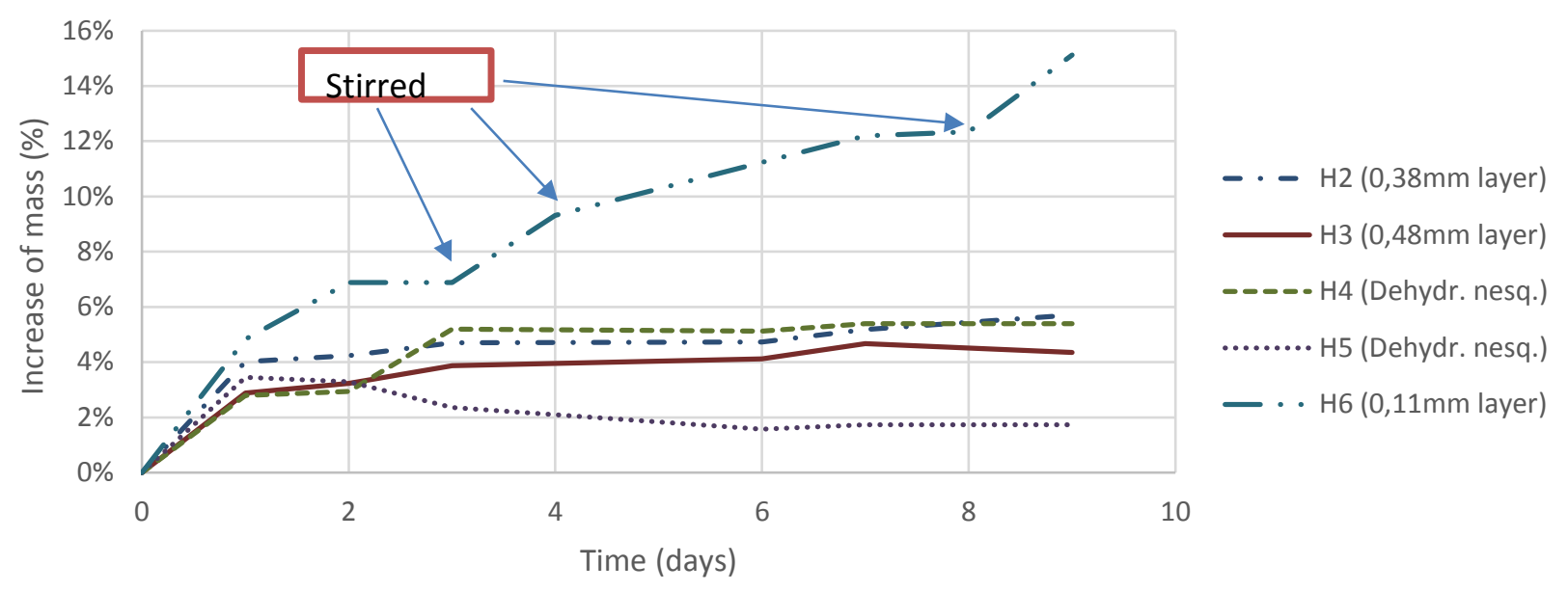

Figure 5. Hydration of $\mathrm{MgCO}_{3}$ powder ( $\mathrm{H} 2, \mathrm{H} 3$ and $\mathrm{H6}$ ) layers of various thickness and dehydrated $\mathrm{NQ}$ ( $\mathrm{H} 4$ and $\mathrm{H} 5$ ) for 1-9 days. Sample $H 2$ is stirred for 10 minutes three times.

The reaction rate for the heat charging process step is sufficient, with a two hours reaction time where direct thermal conduction in the reactor is used. Considering that the system would be used for seasonal and partly daily heat storage, the process may be allowed several days or weeks to be charged, allowing for a lower thermal conductivity to be used in a potential system.

\subsection{Hydration of $\mathrm{MgCO}_{3}$ Powder}

In order to release the energy stored in the process, the hydration of $\mathrm{MgCO}_{3}$ should be confirmed and the kinetics quantified. Various layers of fine $\mathrm{MgCO}_{3}$ powder, 0.11 $\mathrm{mm}, 0.38 \mathrm{~mm}$ and $0.48 \mathrm{~mm}$ thick layers on filter paper were tested in the hydrations procedure described earlier in section 2.4. Shown in Figure 5, the increase of mass by hydration after two days for the samples were $6.8 \%, 4.2 \%$ and $3.3 \%$, respectively, and longer reaction time seemed not to increase the mass noticeably. Considering the complete hydration of $\mathrm{MgCO}_{3}$ according to reaction (R1) give a mass increase of $64.1 \%$, these result are poor. However, the results implied that a larger layer surface area of the powder stack gives better contact between the moisture and the powder and then better hydration.

This gave the idea of stirring the $\mathrm{MgCO}_{3}$ powder samples at certain times. Shown in Figure 5, sample $\mathrm{H} 2$ was stirred three times for better contact between the reactants. At 72 hours, after 10 minutes of stirring, the material was again hydrated for 24 hours, resulting in a total $9.3 \%$ increase of mass. At 96 hours, another 10 minutes of stirring was done, and after the following 72 hours the total mass increase was $12.2 \%$. However, an additional 24 hour of hydration without stirring did not result noticeable mass increase. Again, after stirring after 8 days, the next 24 hours of hydration resulted in a total $15.1 \%$ increase of mass.

\subsection{Silica Gel and Nesquehonite Mixtures}

As mentioned earlier, studies of several authors using $\mathrm{MgSO}_{4}$ as for thermal storage is integrated in zeolite or silica gel (SG) for better mass transfer of the water vapour to crystal water $[3,4]$.

Regarding tests done with SG, the approach was not the same, integrating the salt with the porous water absorbing molecules. The $\mathrm{MgSO}_{4}$ will form thin impenetrable crust, but tests showed that NQ adsorbs and/or absorbs water when stirring the powder, which presumably means that the contact of the gas and the material needs to be improved, but not necessarily a crust layer needs to be avoided.

A few preliminary experiments were done to prove that the reaction $\mathrm{R} 1$ is reversible, without stirring (which is possibly insufficient in the time window of seasonal operations time), instead using SG for a better contact, in a mechanically passive process. The silica gels properties to absorb moisture and physically connected or attached to the $\mathrm{MgCO}_{3}$ will improve the contact between the gas and the solid, enhancing water adsorption on $\mathrm{MgCO}_{3}$ via water absorption on SG.

To analyse the water incorporating properties of the $\mathrm{MgCO}_{3}$ powder and the $\mathrm{MgCO}_{3}$ produced by dehydrating NQ, these were mixed with both wet (fully water absorbed SG) and dry SG (particle size $0.5-1 \mathrm{~mm}$ ) was tested with the setup described earlier. The use of wet SG is to examine the general incorporation capacity of the two minerals with better access to water. However, the results are not usable for examining the overall performance of the hydration process, as when dry SG is used for improving the contact between $\mathrm{MgCO}_{3}$ and moisture vapour. The mass increase in Figure 6 was determined after separating the $\mathrm{SG}$ and the $\mathrm{NQ} / \mathrm{MgCO}_{3}$ with a $0.5 \mathrm{~mm}$ sieve. The hydrated $\mathrm{MgCO}_{3}$ was dehydrated at $65^{\circ} \mathrm{C}$ to determine the mass of water incorporated.

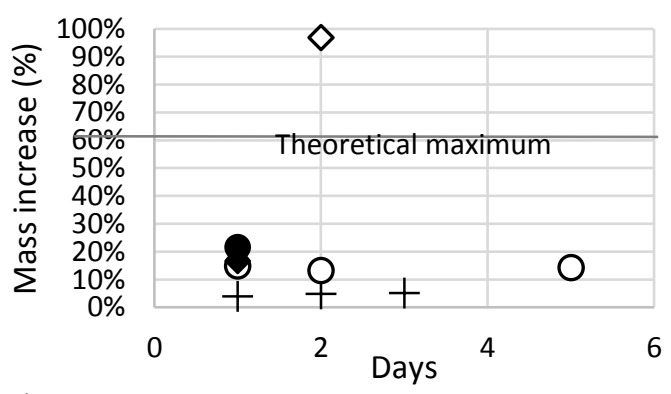

$+0 \mathrm{~g} / 3 \mathrm{~g} \mathrm{SG}+\mathrm{MgCO} 3$

- $3 g / 3 g$ SG $+\mathrm{MgCO} 3$

$06 \mathrm{~g} / 3 \mathrm{~g} \mathrm{SG}+\mathrm{MgCO} 3$

$\diamond 3 \mathrm{~g} / 3 \mathrm{~g}$ SG + NQ re-hydrated

$\checkmark 3 \mathrm{~g} / 3 \mathrm{~g}$ dry SG + NQ re-hydrated

Figure 6. Hydration and mass increase of powder $\mathrm{MgCO}_{3}$ or dehydrated $N Q$ mixed with wet or dry SG. 


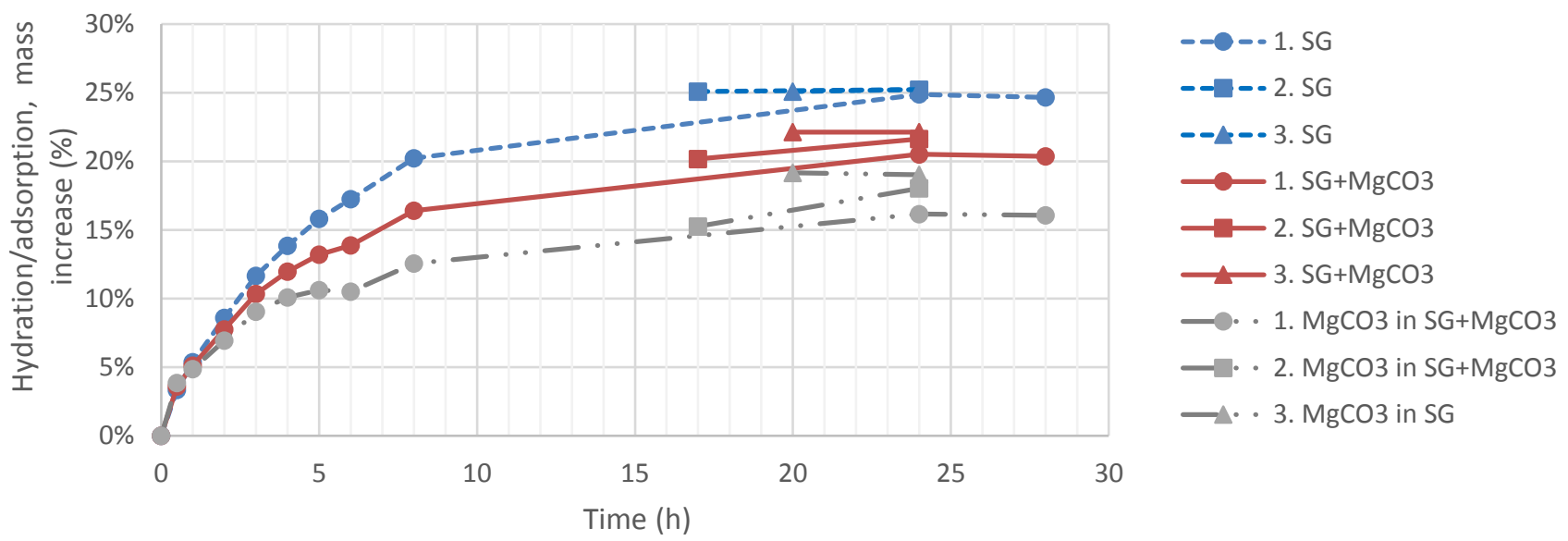

Figure 7 - Hydration measured in mass increase of granular mixture of $\mathrm{SG}$ and $\mathrm{MgCO}_{3}$, a reference material $\mathrm{SG}$, and a theoretical hydration of $\mathrm{MgCO}_{3}$.

Anhydrous $\mathrm{MgCO}_{3}$ powder mixed with dry SG showed a mass increase under $3 \%$. Therefore, $3 \mathrm{~g}$ and $6 \mathrm{~g}$ wet $\mathrm{SG}$ mixed with $3 \mathrm{~g} \mathrm{MgCO}_{3}$ powder was tested for comparison with tests without SG, as well as both dry and wet SG where with dehydrated NQ. Using $\mathrm{MgCO}_{3}$ powder a longer reaction time did not improve the hydration and a $6 \mathrm{~g}+3 \mathrm{~g}$ $\mathrm{SG}+\mathrm{MgCO}_{3}$ mix gave about $15 \%$ of mass increase with $\mathrm{MgCO}_{3}$ resulting in a $23.4 \%$ conversion based on reaction $\mathrm{R} 1$. The mix of $3 \mathrm{~g}+3 \mathrm{~g} \mathrm{SG}+\mathrm{MgCO}_{3}$ gave the best result after 6 hours, with a mass increase of $21.5 \%$. However, the mass increase was smaller with longer reaction time, shown in Figure 6. These results are fairly similar to the test with stirring, and is presumably the maximum water adsorbed or absorbed, and therefore not usable for the reversible process described earlier. Dehydrated NQ mixed with SG gave a mass increase of almost $100 \%$. Considering that $100 \%$ conversion to NQ is a mass increase of $64.1 \%$, besides adsorption, presumably absorption was taking place. Moreover, the water in the wet SG was about $35 \%$ of the total mass of the dehydrated NQ, indicating that almost about $65 \%$ of the water came from the gas. Test with dehydrated NQ and dry SG gave a mass increase of $16.7 \%$, being the best result where $\mathrm{MgCO}_{3}$ has adsorbed water vapour in these preliminary tests.

Therefore, more extensive experiments with improving contact between NQ and SG for better adsorption were made, reported in next section. This indicates that the dehydrated NQ forming $\mathrm{MgCO}_{3}$ gives considerably better water incorporation compared to the $\mathrm{MgCO}_{3}$ powder, having a crystal structure that better adsorbs and absorbs water. As mentioned earlier, according to Strömme et al., after two weeks magnesium hydro carbonates will remain in their original form is not the case with the $\mathrm{MgCO}_{3}$ powder [14]. However, the dehydrated NQ, seems to adsorb the water vapour reversibly, and presumably faster.

\subsection{Granules and Cake of Silica Gel and Nesquehonite Mixtures \\ 4.4.1 Preparations of the Granules}

For extensive testing and determining the hydration effects, two different types of NQ and SG mixtures were made, with better physical contact compared to the earlier tested mixed dry powders. Granules sized 3 - $6 \mathrm{~mm}$ with 3 $\mathrm{g}$ dry of SG with the particle size $0.5-1 \mathrm{~mm}$ and powdered NQ (equivalent mass of $3 \mathrm{~g} \mathrm{MgCO}_{3}$ ) and $1 \mathrm{~g}$ water were produced. Dehydration of the granules at $65{ }^{\circ} \mathrm{C}$ showed similar mass decrease compared to the earlier dehydration test, with the lower water content of the SG taken into account. However, for the bigger particles (granules), compared to the powder, in the dehydrations tests combined with SG material added, dehydrations kinetics were slower, requiring 30-60 minutes more.

\subsubsection{Hydration of the Granules}

Three 28-hour hydration tests of the granules were made, with results shown in Figure 7. A reference sample of SG was added to the reactor, to calculate the mass increase of water vapour adsorption in $\mathrm{MgCO}_{3}$ in the granules. Shown in Figure 7, tests 1-3 resulted in a mass increase between $20.5 \%$ and $22.1 \%$, and for each experiment the hydration increased compared to the previous one. Assuming the SG in the granules behaving as the reference SG sample, the mass increase of $\mathrm{MgCO}_{3}$ (dehydrated NQ) for Test 1, 2 and 3 is $16.2 \%, 18.0 \%$ and $19.0 \%$, respectively. Another experiment, not shown in the figure, (test 4, not shown here) was done with the same sample at 48 hours in $5^{\circ} \mathrm{C}$ giving a mass increase of $15 \%$ and 48 hours at $20^{\circ} \mathrm{C}$ giving a mass increase of $24 \%$, giving a mass increase of $23.4 \%$ for the $\mathrm{MgCO}_{3}$. This results in $36.5 \%$ conversion of hydration according to reaction $\mathrm{R} 1$ $\left(\mathrm{MgCO}_{3}\right.$ hydrating to NQ), with a theoretical mass increase of $64.1 \%$. The heat capacity calculated of the conversion compared to heat capacity of the theoretical values gives for test 3 a capacity of $0.37 \mathrm{MJ} / \mathrm{kg}$ and for test $40.41 \mathrm{MJ} / \mathrm{kg}$, which are about 2.2-2.4 times larger compared to water heated up by $40^{\circ} \mathrm{C}$. However, the increasingly good results obtained with the granules indicate that still better hydration results are possible.

The calculation accuracy of the reference sample may be compromised, considering that SG particles inside the granules may not be reached by the water vapour, assuming that NQ does not release moisture at $20^{\circ} \mathrm{C}$ the same way as $\mathrm{SG}$ does. If this is the case, smaller granules, bigger or longer particle structures of SG particles could be tested in future work, in order to reach higher levels of adsorption.

\subsubsection{Preparation of the Filter Cake}

The volume of thermal energy storage is preferable as small as possible and one of the main objectives is using denser compounds than water for thermal storage. Spherical granules will however, create some empty space of gas or air, increasing the volume of the system. For better density and more simple mixing of the components, NQ was suspended and mixed with SG of a $0.5-1 \mathrm{~mm}$ particle size. 
The suspension was filtered and stirred simultaneously for better distribution of the two components. In the first two experiments the solution from which of NQ was precipitated and containing unreacted $\mathrm{MgSO}_{4}$, according to reaction $\mathrm{R} 5$, was mixed with $\mathrm{SG}$, and then filtered. In test 1 the filter cake was washed once, and in test 2 twice. Washing is important, as the $\mathrm{MgSO}_{4}$ can form an impenetrable crust on its surface [3]. Before the hydration tests, the material was dehydrated at $65^{\circ} \mathrm{C}$ for three hours.

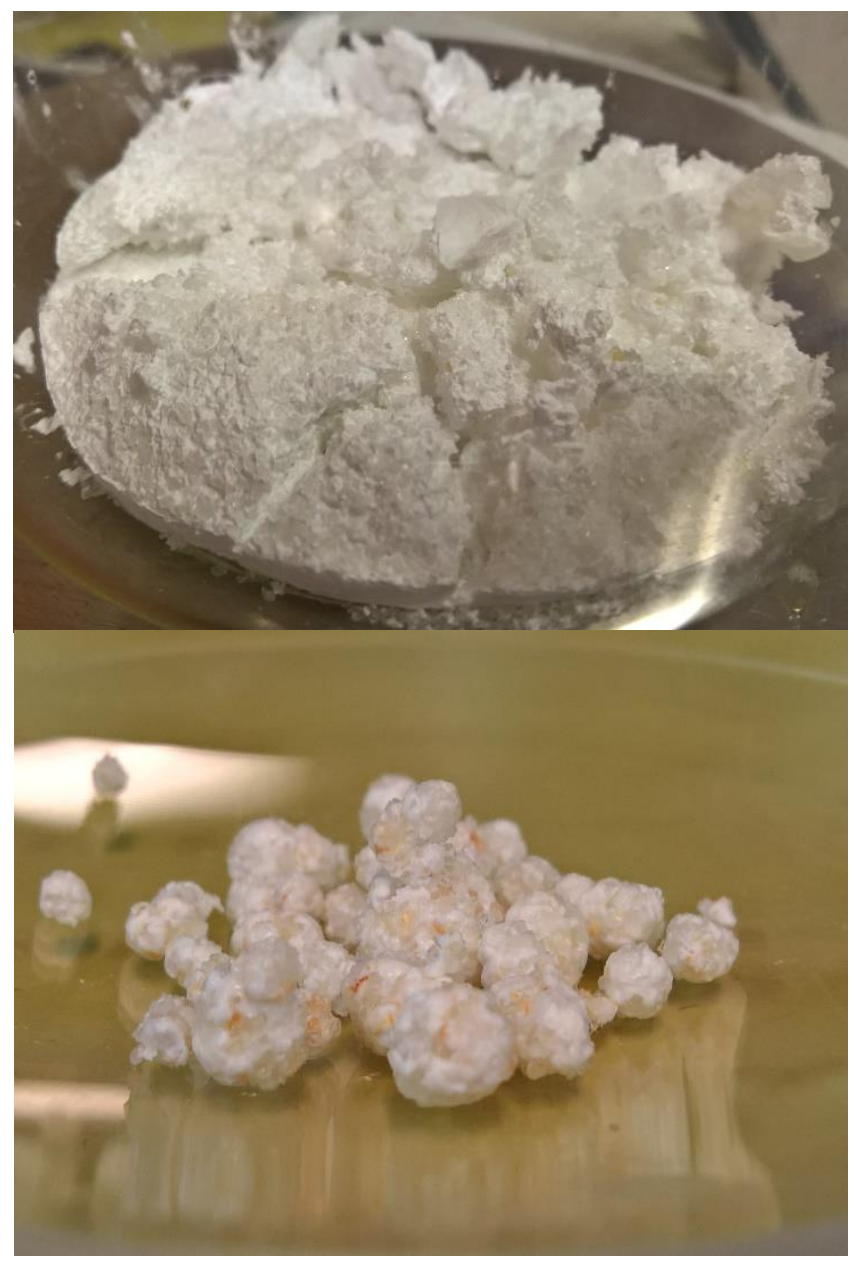

Figure 8. Top (8a): filtration cake of $N Q$ and $S G$ mixture. Bottom (8b): granules of $N Q$ and $S G$.

\subsubsection{Hydration of the Filter Cake}

Shown in Figure 9, in test 1, the mass increase was under $1 \%$ during two days while in test 2 , the mass increase reached $16 \%$ after five days. The unexpected low reactivity of test 1 was assumed to be caused by deposits of $\mathrm{MgSO}_{4}$ from the solution where in NQ was produced, forming an impenetrable crust blocking the necessary contact for the hydration. In test 3 (the material is shown in Figure 8a), the NQ filter cake was washed twice, mixed with clean water containing $\mathrm{CO}_{2}$ and filtered and washed again to remove as much $\mathrm{MgSO}_{4}$ as possible, being about $5 \mathrm{~mm}$ thick and giving a mass increase of $17 \%$.

Another hydration (test 3.2) was done with the material used earlier in test 3 . In test 3 , it was noticeable, that during dehydration, despite the temperature of the reactor being 65 ${ }^{\circ} \mathrm{C}$, the temperature inside the cake was $10-15^{\circ} \mathrm{C}$ lower after three hours. However, the mass decrease after 3 hours stopped, although it continued to fluctuate. As these materials characteristically absorb heat, the temperature of $65^{\circ} \mathrm{C}$ was not reached inside the cake, the conversion of the dehydration reaction was not close to $100 \%$ according to the results in section 4.1. Therefore, the dehydration time was increased with two hours. The result was a mass increase of $19.8 \%$ in the hydration step, which is $3 \%$ larger than test 3 , and comparable with the test with the hydration tests with granules. However, the kinetics are roughly 5 times slower. The early tests with $\mathrm{MgCO}_{3}$ powder and dehydrated NQ, showed that these are not favourable for water transport, presumably trapping SG particles inside and compromising the hydration results. Therefore, calculating the hydration of $\mathrm{MgCO}_{3}$ (about 15\%) using the reference SG may not be accurate. The theoretical mass increase of hydrating $\mathrm{MgCO}_{3}$ to NQ (reaction $\mathrm{R} 1$ ) is $64.1 \%$, as mentioned earlier.

\subsection{Excess Water of Dehydration}

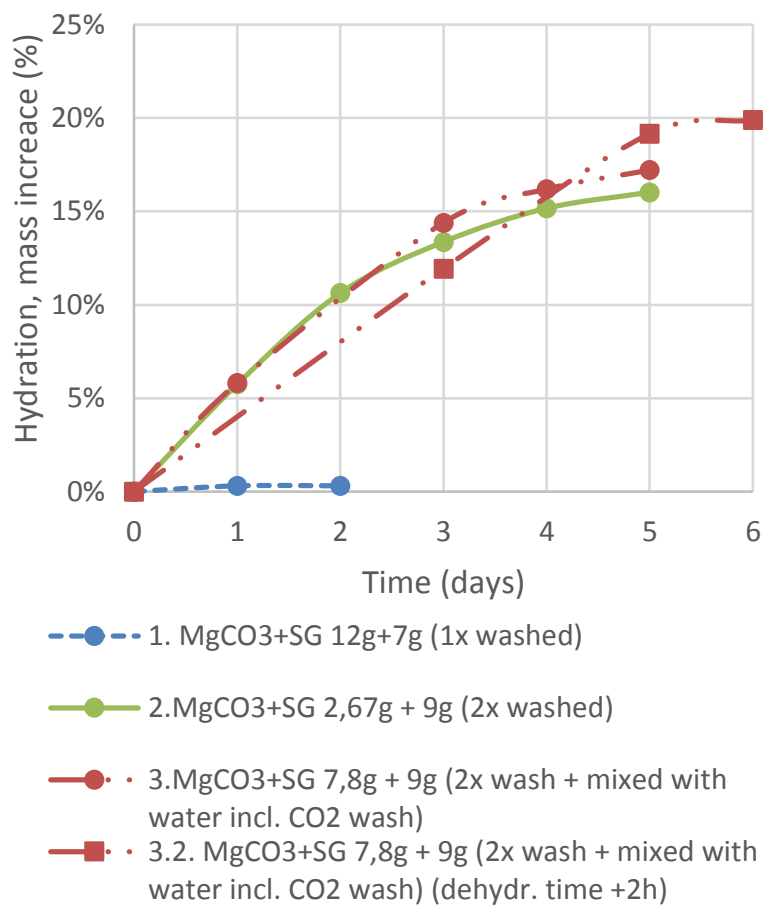

Figure 9. Hydration of $\mathrm{MgCO}_{3}$ mixed with SG filter cakes. Test 1,2 and 3 are different samples, while test 3 and 3.2 where done with the same sample.

As mentioned earlier, large amounts of water vapour are released during the dehydration. According to Morgan et al. an open and dry system for dehydrating NQ is considerably more efficient compared to trapping the water in a closed system [13]. Using a closed system for the process, the water vapour needs to be collected to avoid pressurising the system and condensation of water. Studies suggest that an open system could be used, using humidity from the outside air [3]. However, it could result in large heat losses in colder locations where mainly air inside a building is heated. Using nesquehonite for TES will emit $\mathrm{CO}_{2}$ forming stable hydromagnesite at atmospheric vapour pressure of $\mathrm{CO}_{2}[12,18]$. These conditions require a closed system when using magnesium hydro carbonates for a TES.

\section{Acknowledgements}

The authors want to acknowledge Erkki Paasikiven Säätiö and K.V. Lindholms Stiftelse for financial support for this work. 


$\begin{array}{ll}\begin{array}{l}\text { Nomenclature } \\ \text { CCSM }\end{array} & \begin{array}{l}\text { Carbon capture and storage by } \\ \text { mineralisation }\end{array} \\ \text { NQ } & \text { Nesquehonite } \\ \text { SG } & \text { Silica gel } \\ \text { TES } & \text { Thermal energy storage }\end{array}$

\section{Conclusions}

Conversion and reaction rate experiments on hydration and dehydration of magnesium hydro carbonates to examine its availability for thermal energy storage were done. The charging step of the thermal energy storage using magnesium hydro carbonates, the dehydration of the nesquehonite (NQ), is sufficiently fast at low temperatures as $50{ }^{\circ} \mathrm{C}$ and the reaction is about $90 \%$ completed after 120 minutes. Higher temperatures such as $60{ }^{\circ} \mathrm{C}$ approved the conversion by a few $\%$, but at $65{ }^{\circ} \mathrm{C}$ the conversion was almost $100 \%$ after 90 minutes and the kinetics considerably faster. The heat discharging step, the re-hydration required good contact between the humid air and $\mathrm{MgCO}_{3}$. During two days hydration, of a $\mathrm{MgCO}_{3}$ powder layer $0.11 \mathrm{~mm}$ showed a mass increase of $6.8 \%$. Adding short stirring sessions to the process gave a mass increase of $15.1 \%$, which equals to about $25 \%$ of conversion. Re-hydration of granulated NQ and Silica Gel mixtures gave a conversion of $37 \%$ after 24 hours. However, granules showed four times faster kinetics than filter cakes of the mixture. Increasing the conversion to $80-90 \%$ and faster kinetics are the goal of ongoing work. Moreover, investigations how the material would be used in a thermal energy storage process system are ongoing.

\section{References}

[1] K. Edem N'Tsoukpoe, H. Liu, N. Le Pierrès, L. Luo, "A review on long-term sorption solar energy storage," Renewable Sustainable Energy Reviews, 13, 23852396, 2009.

[2] M. van Essen, A. H. Zondag, R. Schuitema, W. G. T. van Helden, C. C. M. Rindt, "Characterization of $\mathrm{MgSO}_{4}$ Hydrate for Thermochemical Seasonal Heat Storage," Journal of Solar Energy Engineering, 4, 419-427, 2008.

[3] S. Hongois, F. Kuznik, P. Stevens, J-J. Roux., "Development and characterization of a new $\mathrm{MgSO}_{4}$ zeolite composite for long-term thermal energy storage," Solar Energy Material \& Solar Cells, 95, 1831-1837, 2011

[4] G. Whiting, D. Grondin, S. Bennici, A. Auroux, "Heats of water sorption studies on zeolite- $\mathrm{MgSO}_{4}$ composites as potential thermochemical heat storage materials," Solar Energy Material \& Solar Cells, 112, 112-119, 2013.

[5] M. A. Tahat, "Heat-pump/energy-store using silica gel and water as a working pair," Applied Energy, 69, 1927, 2001.

[6] A. F. Lele, F. Kuznik, H. U. Rammelberga, T. Schmidt, W. K. L. Rucka, "Thermal decomposition kinetic of salt hydrates for heat storage systems," Applied Energy, 154, 447-458, 2015.

[7] H. Müller-Steinhagen, "Applications of solar heat for temperatures ranging from $50-2000^{\circ} \mathrm{C}$," in 5 th
European Thermal-Sciences Conference, Eindhoven, The Netherlands., 2008.

[8] R. Zevenhoven, M. Slotte, J. Åbacka, J. Highfield, “A comparison of $\mathrm{CO}_{2}$ mineral carbonation processes involving a dry or wet carbonation step," Energy, 177, 604-611, 2016.

[9] R. Erlund, E. Koivisto, R. Zevenhoven, "Extraction of magnesium from four Finnish magnesium silicate rocks for $\mathrm{CO}_{2}$ mineralisation - Part 2: Aqueous solution extraction," Hydrometallurgy, 166, 229-236, 2016.

[10]E. Koivisto, R. Erlund, R. Zevenhoven, "Extraction of magnesium from four Finnish magnesium silicate rocks for $\mathrm{CO}_{2}$ mineralisation - Part 1: Thermal solid/solid extraction," Hydrometallurgy, 166, 222$228,2016$.

[11] W-Z. Yin, Y-L. Wang, Q-D. Ji, J. Yao, Y. Hou, L. Wang, W-X. Zhong, "Synthesis and formation mechanism of micro/nano flower-like $\mathrm{MgCO}_{3} \cdot 5 \mathrm{H}_{2} \mathrm{O}$," Int. Minerals. Metallurgy Materials, 21, 304-310, 2014.

[12] R. J. Hill, J. H. Canterford, F. J. Moyle, "New data for lansfordite,” Mineralogical Magazine, 46, 453-7, 1982.

[13] B. Morgan, S. Wilson, I. Madsen, J. Gozukara., "Increased thermal stability of nesquehonite $\left(\mathrm{MgCO}_{3} \cdot \mathrm{H}_{2} \mathrm{O}\right)$ in the presence of humidity and $\mathrm{CO}_{2}$ : Implications for low-temperature $\mathrm{CO}_{2}$ storage," Int. Gas Control. 39, 366-376, 2015.

[14]HSC Chemistry version 8.1.1. (2014). Pori, Finland: Outokumpu Research.

[15] M. Strömme, A. Mihrayan, J. Gómez, S. Frykstrand (2015). Anhydrous, amorphous and porous magnesium carbonates and methods of production thereof. 20150298984 A1

[16] P. Ballirano, C. De Vito, V. Vincenzo Ferrini, S. Mignardi, "The thermal behaviour and structural stability of nesquehonite, $\mathrm{MgCO}_{3} \cdot 3 \mathrm{H}_{2} \mathrm{O}$, evaluated by in situ laboratory parallel-beam $\mathrm{X}$-ray powder diffraction: New constraints on $\mathrm{CO}_{2}$ sequestration within minerals," Journal of Hazardous Materials, 10, 522-528, 2010.

[17] L. A. Hollingbery, T. R. Hull, "The fire retardant behaviour of huntite and hydromagnesite - A review," Polymer Degradation and Stability, 95, 2213-2225, 2010.

[18] G. Jauffret, J. Morrison, F. P. Glasser, "On the thermal decomposition of nesquehonite," Journal of Thermal Analysis and Calorimetry, 122, 601-609, 2015. 